El poeta y su mito: ¿la siena como destino del lenguaje poético? Estudio de Sirenas...

\title{
EL POETA Y SU MITO: ¿LA SIRENA COMO DESTINO DEL LENGUAJE POÉTICO? ESTUDIO DE SIRENAS, DE ÁNGEL GONZÁLEZ Y VALERIA DOCAMPO
}

\author{
Bénédicte MATHIOS \\ Université Blaise Pascal \\ Benedicte.MATHIOS@univ-bpclermont.fr
}

\begin{abstract}
Pirenas ${ }^{1}$ es el único libro para niños escrito por Ángel González ${ }^{2}$, cuya obra poética y crítica corre a lo largo de los años 1956 a 2001³. Sirenas fue publicado después de su muerte en 2011. El libro, cuyo texto está reunido al final del libro, antes de las biografías respectivas del poeta y de la dibujante Valeria Docampo que lo ilustra, consta de diez dobles páginas enteramente cubiertas por diez láminas, en las cuales se insertan los movimientos del poema, careciendo de texto la última doble página. Si las clasificamos desde el punto de vista métrico, las distintas etapas del poema constan de:
\end{abstract}

$>$ un cuarteto-lira con un endecasílabo, un heptasílabo, dos endecasílabos,

$>$ una silva modernista de cinco versos con un tetrasílabo, un heptasílabo, tres endecasílabos,

$>$ una silva libre de seis versos con un pentasílabo, tres heptasílabos, dos endecasílabos,

$>$ un cuarteto asonantado con un octosílabo, tres endecasílabos,

$>$ un cuarteto asonantado con un octosílabo, tres endecasílabos,

$>$ un cuarteto con un eneasílabo, un endecasílabo, un tetrasílabo, un alejandrino,

$>$ un terceto, con un endecasílabo, un heptasílabo, un octosílabo, un cuarteto con endecasílabos,

\footnotetext{
${ }^{1}$ Ángel González, Valeria Docampo, Sirenas, Madrid, Veintisiete Letras, 2011.

${ }^{2}$ Es probablemente parte de un conjunto más amplio de poemas que preparaba el poeta, basado en una representación «de tono juvenil y festivo» de los meses del año, como señalan Luis García Montero y Jesús García Sánchez en el preámbulo del también póstumo poemario Nada grave (Madrid, Visor, 2008, p. 13).

${ }^{3}$ Palabra sobre palabra reúne la poesía escrita hasta 1994, Otoños y otras luces se publicó en 2001, el poemario Nada grave fue publicado después de su muerte, en 2008. Entre las publicaciones críticas, podemos destacar Juan Ramón Jiménez (1973), Antonio Machado (1986), y la reunión de sus artículos, La poesía y sus circunstancias (2005).
} 
un terceto con un heptasílabo, un endecasílabo, un dodecasílabo.

La polimetría, característica de la obra gonzaliana, conjuntamente con unas dominantes métricas, y una articulación compleja de la sintaxis con la métrica, vienen a participar en la construcción de este poema.

Como contestando estos rasgos métricos, el poema tiene una forma narrativa y dialogística, forma híbrida que cabe estudiar, y que se conecta lógicamente con el resto de la obra gonzaliana. Sin embargo, resulta original en la obra que la diégesis se base en un mito ${ }^{4}$ y en una figura ${ }^{5}$ mítica, la de la sirena, cuyos orígenes literarios son múltiples, entre los cuales el más famoso de todos es su representación en la Odisea de Homero ${ }^{6}$. El poeta saca del mito los siguientes componentes: la figura de la sirena y su apariencia ${ }^{7}$, su carácter psicológico típico y tópico, en especial el papel desempeñado por su voz, y los inserta en una diégesis contada en versos, ofreciendo la presencia de esta figura múltiples significados.

Otra característica esencial, en este poema tanto como en el conjunto de la obra gonzaliana, es el trabajo sobre el significante y sus sonoridades. Antanáclasis, dilogías, paronomasias, figuras sonoras con las que juega el poeta ${ }^{8}$, transforman el sentido de ciertas palabras sobreimprimiendo sentidos unos a otros y niveles de lectura a otros. De ahí, como lo veremos, varios destinatarios potenciales, entre los cuales los niños, pero, también, los adultos. Es así como la representación de la mujer que se desprende del corto relato en versos, viene aquí completando el resto de la obra en su vertiente satírica, a sabiendas de que también existe una vertiente seria, en la que la figura femenina y amada participa en la búsqueda de un lenguaje poético que sea capaz de restituir las sensaciones de la experiencia vital.

En cuanto a los significados del poema-libro, son múltiples: si una dimensión trágica dimana del sentido general de la narración, una visión humorística y hasta satírica de las costumbres sociales, viene a contradecir en apariencia dicho aspecto. A esta doble dimensión, se añade, a través de la figura de la sirena, una encarnación de la relación del yo con el lenguaje poético o sea con la realidad ${ }^{9}$, lo cual es una manera de reactivar el mito de la sirena ${ }^{10}$, basado en el tema del deseo, un deseo de varias índoles, tanto intelectual, como erótico.

\footnotetext{
${ }^{4}$ La única excepción de una referencia explícita a los mitos antiguos siendo el soneto «Danae» en el poemario de 1956 Áspero mundo.

${ }^{5}$ Nociones cuyos contornos están definidos por Véronique Leonard-Roques, en la introducción a Figures mythiques: Fabrique et métamorphoses, Études réunies et présentées par Véronique Léonard-Roques, Clermont-Ferrand, PUBP, 2008, pp. 9-21.

${ }^{6}$ Annie Lermant-Parès, «Les sirènes dans l'Antiquité», en Dictionnaire des mythes littéraires, sous la direction du professeur P. Brunel, Monaco-Ville, Editions du Rocher, 1988, pp. 1289-1293.

${ }^{7}$ Muchos detalles históricos sobre la evolución de estos aspectos los aporta el libro de M. Bettini et L. Spina Le Mythe des Sirènes (Paris, Belin, 2010).

${ }^{8}$ Léase José Luis García Martín, Guía para un encuentro con Ángel González. Oviedo, Luna de Abajo, 1997, pp. 80-95.

${ }^{9}$ Dado que, como lo escribe Ángel González, «la poesía que prefiero es la que lo conserva todo: la figura del mundo y el mundo figurado» (Ángel González, La poesía y sus circunstancias. Barcelona, Seix Barral, 2005, p. 483), lo cual implica el carácter inseparable del trabajo sobre las palabras y de la toma en cuenta de la realidad.

${ }^{10}$ Así se define la noción de «hipertextualidad mítica». Véase Ivanne Rialland, «Mythe et hypertextualité», en http://www. fabula.org/atelier.php?Mythe_et_hypertextualit\%26eacute\%3B (última consulta, 30-12-2014).
} 
La primera cuarteta, escrita en blanco en el fondo oscuro de la página de izquierda que figura el cielo nocturno con una inmensa luna llena, sitúa el espacio-tiempo de una narración en primera persona: la soledad del sujeto, el momento, el sitio, el anuncio de «un episodio extraordinario» configuran una captatio benevolentiae que seduce por su sencillez y su misterio tanto al lectorado joven como al lectorado adulto. Desde el punto de vista visual, contrasta la tinta blanca del texto sobre lo oscuro del cielo nocturno, participando este color blanco de la luz lunar que domina lo alto de la página, pues se sale de la luna enorme que ilumina el mar y el personaje del locutor.

La doble página siguiente se centra en la visión del sujeto lírico, cambiando así la perspectiva del lector, que a partir de este momento mira la escena con los ojos del locutor, en el espacio poético de una silva de cinco versos, esta vez en tinta negra sobre lo blanco del agua «alumbrada» por la luz de la luna, agua de la que emergen, como si de figuras verdaderas se tratara, dos sirenas; se les describe rápidamente como jovenzuelas, insistiendo el narrador-locutor en la largura de su pelo, sin más elementos referidos al mito, y se anuncia un inicio de diálogo entre las dos figuras marítimas. La inclusión de figuras con connotado mítico no cambia nada del realismo de la escena. Esta naturalidad bien se articula con la voluntad de narrar una anécdota cotidiana en la que surge lo extraordinario.

A continuación, el diálogo, bien marcado con guiones, se desarrolla, de nuevo, en tinta blanca sobre el fondo oscuro de la página izquierda siguiente (y de las tres siguientes), rodeado por una representación submarina, con peces de distintos tamaños, nadando las dos sirenas entre ellos, tocándolos, casi amalgamadas a ellos, incluso su pelo, larguísimo, tanto como sus colas. Es en estas páginas, evocando otro mundo que el cotidiano, no sin aludir a él, en las cuales se desarrollan las alusiones a las sirenas y la Odisea de Ulises, y, conjuntamente, los juegos de palabras que las asocian a una representación específica de la realidad, el mito y sus figuras características sirviendo de matriz a una reflexión sobre las capacidades expresivas del lenguaje y sus peligros.

Es así como, en el primer diálogo, el léxico del mar y de los peces, viene a sustituirse a un léxico corriente y esperado. La homofonía entre las palabras «Ola» y «hola», cobra una función fática, a la vez que su reiteración representa el movimiento marítimo, sin límites: «Ola, ola, ola, ola». A partir de esta primera intervención, las palabras «ola», «delfín», «mero», «barbo», «ostra», «alga» son desviadas de su sentido inicial: recrean el medioambiente marítimo para significar el cómputo cotidiano del tiempo, «ola» reemplaza «hora», «delfines», «mero», «barbo», «ostra», son unidades designando el cómputo del tiempo (horas, minutos etc.). En los siguientes versos, cabe notar los juegos de palabras que, bajo la dominación de las vocales «a»y «0», sustituyen palabras por otras, con dobles sentidos, infantiles a la vez que eróticos. De ahí la cadena de palabras: «alga» / «nalga» / «traigo» / «cola», con paronomasia entre «alga» $\mathrm{y}$ «nalga», dominación de las oclusivas «g», «c», juegos sobre las vocales: a, a, a, a, a, o, o, a. Claro está que de «alga» (sustituyéndose in absentia a «algo»), al volverse «nalga» (que tiene como su negación incluida en la «n» de nalga, forma implícita de respuesta negativa a la pregunta « ¿Tienes alga que hacer?»), le da al poema una dimensión divertida que en tono lúdico transforma la figura de la sirena en una figura de mujer cuyo cuerpo erótico está tomado en cuenta: «no tengo nalga pero traigo cola». Prosigue el poeta con las figuras paronomásticas en las 
páginas 6 y 7, jugando con un vocabulario recreado a partir del medioambiente marítimo y también a partir de los medios de comunicación modernos: «Nada», repetido cuatro veces en el primer verso, forma una dilogía entre el imperativo de «nadar» y el adverbio «nada», «ola» sigue siendo un equivalente de la palabra «hora», y «caracola» se sustituye a «teléfono». El movimiento siguiente participa en esta manipulación de los lugares comunes de la conversación: una antanáclasis se construye entre las dos ocurrencias del significante «sal» (sustantivo e imperativo del verbo «salir»), construido en quiasmo en un verso escalonado, entre el adverbio «solo» y el adjetivo «sola». El quiasmo se mantiene en los dos versos siguientes entre «ola»y «adiós»: «-Ola, ola y adiós. / -Adiós y ola, ola, ola».

Los dos enunciados siguientes, llevados por dos cuartetas heterométricas asonantadas, contienen un discurso en boca de las dos sirenas, y el «nosotros» se sustituye así al «yo». De ahí que el contenido de la primera estrofa permite identificar las dos figuras de sirenas representadas a la figura mítica original (por lo menos la de Homero) ${ }^{11}$ de la sirena: en efecto, el discurso de los dos personajes evoca una posibilidad para ocuparse y divertirse, la cual remite al papel principal que les atribuye Homero ${ }^{12}$ a las sirenas, antes de contar cómo Ulises así como su tripulación escapan a su canto gracias a la ayuda de Circé:

$$
\begin{aligned}
& \text {-Podríamos acercarnos } \\
& \text { de aquel barco velero hasta la popa } \\
& \text { y cantar a dos voces las canciones } \\
& \text { que a las tripulaciones vuelven locas. }
\end{aligned}
$$

La crueldad que revela el proyecto es implícita, pues forma parte de la figura en sus orígenes literarios, y viene con aparente naturalidad a completar el diálogo trivial con léxico recreado de la estrofa anterior. En la segunda cuarteta, se confirma esta filiación mítica, tomándose en cuenta otra vez el enfoque de las dos sirenas. Lo trágico se desprende de esta crueldad - ¿femenina? -, tonalidad que ofrece a veces el resto de la obra, en la que la representación de la mujer es ambivalente: sensual, suave, lírica hasta ligada a la creación poética ${ }^{13}$, por un lado, y conflictiva, cruel, satírica ${ }^{14}$, por otro lado. En este caso, la palabra dejada a las sirenas le da indirectamente al poema un tono satírico, dada la siguiente antífrasis: «Es divertido ver a los marinos / arrojándose al agua por la borda». La ligereza del tono de la frase se confirma en la continuación del poema: reanudan las sirenas con frases de la vida cotidiana superpuestas al ámbito marino y mítico; la cita de la sirena con el «tritón barbado» acarrea un comentario que vincula este poema con la autorepresentación del locutor. Recordemos que en un poema de 1969, extracto de Breves acotaciones para una biografía, titulado «Mi vocación

\footnotetext{
${ }^{11}$ M. Bettini y L. Spina, en su libro Le Mythe des Sirènes (op. cit.) describen con mucha precisión las distintas apariencias y versiones de las sirenas desde sus orígenes hasta la época contemporánea.

12 Pero también, concerniente a los argonautas, Apolonio de Rodas cuenta el mismo episodio, en el mito de Orfeo y Eurídice.

${ }^{13}$ Por ejemplo en el poemario titulado Áspero mundo (1956), las partes tituladas «Sonetos» y «Acariciado mundo», pero también en los poemas amorosos de Otoños y otras luces (2001).

${ }^{14}$ Por ejemplo en el poemario titulado Prosemas o menos (1986), más particularmente la parte titulada con la siguiente antífrasis: «Poemas amatorios».
} 
profunda» ${ }^{15}$, y situado después de la crisis frente al papel del lenguaje expresada en Tratado de urbanismo (1967), el locutor se compara con un «tritón de alcoba», asimilando su existencia al estallido de su cuerpo en varias realidades humanas. La cita con el tritón anunciada por la sirena, bien podría ser una proyección de esta figura imaginaria del sujeto creada a partir de los años sesenta, distanciada del personaje autobiográfico anteriormente reinventado, jugando con el lenguaje del que ya no se fía, frente a lo estancado de la sociedad que le rodea ${ }^{16}$. Así que, de la misma manera que el relato de Homero pone en abismo en la voz de las sirenas el propio relato del autor (o sea la Ilíada), como lo señala Annie Lermant Parès ${ }^{17}$, la presencia del tritón, el manejo del lenguaje, su transformación, pueden quizá recordar el alcance del mito de los orígenes: la visión abismal del relato y de su transmisión se transforma, en el caso de esta poesía, en una puesta en abismo de la relación compleja del locutor con el lenguaje codificado en el marco de su obra.

Las dos últimas dobles páginas con texto oponen los dos ambientes del libro, el de los fondos submarinos por una parte, el más acogedor, y por otra parte el espacio nocturno alumbrado por la luna en el que se vislumbra la representación gráfica del locutor, y que está dominado por el contraste omnipresente de blanco y negro. Dos tonalidades propias de la poesía gonzaliana se expresan a través de este contraste visual, confirmado por las dos últimas partes del texto del poema-libro. La cuarteta de rimas consonantes representa el final de lo observado por el locutor o sea la partida de las dos sirenas: dos encabalgamientos definen este movimiento de alejamiento. Los delfines, ellos también, que acompañan, tanto en el texto como en el dibujo este movimiento ondulante, forman parte de la veta mítica del poema. La tercerilla final, por su parte, centra el balance de la narración sobre el locutor personal. Esta vez, él desempeña un papel parecido al de Ulises si hubiera fracasado en el intento de escapar a la voz de las sirenas, o después de él el de Jasón: efectivamente, la escena que presenció le impacta hasta el punto de ponerlo en peligro de desaparición, o sea que entra, al quedarse solo, en la lógica de las sirenas, y le amenaza la desaparición, lo cual es uno de los temas claves trágicos de la obra gonzaliana, dominada por la desintegración progresiva del sujeto, y más generalmente del ser humano sometido a la huida del tiempo ${ }^{18}$.

Esta ruptura final manifiesta uno de los rasgos de la escritura gonzaliana, y es así como la última doble página representa un paisaje vacío, como si la figura del sujeto se hubiera tirado efectivamente al agua. El poema es, en este sentido, perfectamente en adecuación con el resto de la obra. También lo son las distintas tonalidades que coexisten, amplificadas por las representaciones pictóricas y los juegos sonoros de palabras. Pero el desaparecer del locutor al final, también puede confirmar, en resonancia con el paratexto, su fascinación por el mundo escondido y por descubrir de las sirenas. Dos

\footnotetext{
15 Ángel González, Palabra sobre palabra, Barcelona, Seix Barral, 1994, p. 242.

${ }^{16}$ Tal y como lo confirma el mismo autor en la Introducción a la antología Poemas: «[...] el hecho de poner énfasis en lo convencional y formulario - los “procedimientos"- es un intento de salir del 'personaje poético' que mis libros anteriores habían configurado» (Ángel González, Poemas, edición del autor, Madrid, Cátedra, 2003 [1ª edición 1980], pp. 23-24).

${ }^{17}$ Op. cit., p. 1292. Homère, Iliade, Odyssée, éditions Gallimard, bibliothèque de la Pléiade, 1955, pp. 716-717.

${ }^{18}$ Léase, entre los primeros poemas de la obra «Para que que yo me llame Ángel González», Palabra sobre palabra, op. cit., p. 13.
} 
elementos lo demuestran: la página interior de título representa una figura del locutor y poeta acurrucado en su baño, escuchando una caracola. Este dibujo paratextual simboliza la intrusión en el contexto de una casa moderna, del misterio submarino que nos va a contar el poeta y también la interioridad de la visión que se nos propone a continuación.

Otros elementos demostrando la atracción del mundo submarino son el trabajo sobre las paronomasias, el uso de otro léxico, reivindicado en otros poemas de la obra ${ }^{19}$, la reactualización y modernización del mito, su alcance metalingüístico, transmitido por la figura mítica de la sirena, tal y como nos lo enseña la sexta doble página, al dejar la sirena protagonista «un mensaje» en una caracola como si de un teléfono se tratara. La voz de la sirena, viene a ser, en eco a la página de título, voz de la inspiración poética, sacada de la materia prima submarina. Otro indicio de la participación del sujeto poético en su propia narración versificada, aparece en las noticias biográficas del final que se refieren a los autores. Se evoca un sueño hecho por el autor, y «su paso por el fondo del mar» contados por el poeta a la dibujante. Que sea verdadero o no este apunte no importa, vale para confirmar la ambivalencia del mito aquí revelada, que el autor no teme enfrentar, dado que en la continuidad de una obra en la que se corrieron muchos riesgos al enfrentarse con el lenguaje y que el contexto político, social, y cultural impactó mucho, decidió el poeta, sin abandonar del todo la veta social y ética, acentuar el carácter a la vez polémico, intertextual, imaginario, y distanciado de su poesía. Por el contrario, la voluntad de permanecer en contacto con la realidad sensible del mundo rodeante, también característica de la obra hasta el final, sigue vigente, y es así como se mezclan elementos de un mundo imaginario con un referente real, el de los encuentros y desencuentros de los seres humanos, hombres y mujeres en el caso de este poema-libro, en una poesía libre y aleatoria ${ }^{20}$ como nos lo enseña la elección de palabras en lugar de otras.

Llama la atención por fin el color dorado, solar de las dos páginas de guarda, que se opone tanto al casi blanco y negro medioambiente desde el que narra el locutor, como a los fondos submarinos dominados por el azul, el verde, aunque se destaquen las dos figuras de las sirenas, en cuyo pelo insi ste la descripción poética. Primero, aquellos amarillos son colores complementarios de los azules oscuros del conjunto y son estas páginas muy gráficas, dibujando grandes ondulaciones las cabelleras de las sirenas, luego, se corresponden bien con la búsqueda de la luz que aparece a lo largo de la obra ${ }^{21}$ y sigue manteniéndose en Otoños y otras luces en 2011 - aunque sea una luz descendiente -. Por fin, el grafismo que caracteriza la representación de las cabelleras y la dominación del amarillo no son sino huella visual de intertextualidad con, por ejemplo, la obra poética Quevedo, de Lope de Vega, y muchos otros...en efecto, asistimos en estas dos páginas a la asimilación visual del pelo dorado

\footnotetext{
${ }^{19}$ Véanse «Luz llamada día trece», «Símbolo» (1961), Palabra sobre palabra, op. cit., p. 93, pp. 105-106.

${ }^{20}$ Léanse en «Poética a la que intento a veces aplicarme» (1977), los siguientes versos: «Escribir un poema: marcar la piel del agua. / Suavemente, los signos / se deforman, se agrandan, / expresan lo que quieren / la brisa, el sol, las nubes [...]» (Palabra sobre palabra, op. cit., p. 291).

${ }^{21}$ Citemos entre otros ejemplos los poemas de los «American landscapes», en Prosemas o menos (1985), que se dedican a evocar una luz crepuscular.
} 
arquetípico de la mujer a las ondas del mar $^{22}$. En la obra de poetas del siglo XX como por ejemplo Gerardo Diego, el paso por debajo del nivel del mar (como pudo pasar también en la obra de Rafael Alberti en «Elegía del niño marinero» ${ }^{23}$ ), significa el paso a otro mundo ${ }^{24}$, paradisíaco por su dimensión inédita, visual, musical y erótica, de la que no está desprovisto el poema de Ángel González.

El poeta y la dibujante consiguen pues con este libro ofrecer una lectura doble, a la que se pueden dedicar varios públicos, desde los más jóvenes que quedarán extrañados («con esperanza», para citar un famoso título del poeta), hasta los más maduros (que lo leerán «sin convencimiento» si consideramos que al destino del ser humano se refiere), pero allende estas dimensiones antitéticas, dominará en sus lecturas la ensoñación asequible a cualquier edad... en la que participan conjuntamente poema e imágenes.

\footnotetext{
${ }^{22}$ Ejemplos famosos: «En crespa tempestad del oro undoso», de Francisco de Quevedo, «A un peine que no sabía el poeta si era de boj o de marfil», de Lope de Vega, etc.

${ }^{23}$ Por ejemplo en la penúltima estrofa: «¿Qué harás, pescador de oro, / allá en los valles salados / del mar? ¿Hallaste el tesoro / secreto de los pescados?», Rafael Alberti, Poesía I, edición de Jaime Siles, Barcelona, Seix Barral, 2013, p. 161.

${ }^{24}$ Por ejemplo en el poema que le contesta al de Lope de Vega y titulado «A un peine que sí sabía el poeta que era de carey», soneto en el que podemos leer :
}

De las más altas crestas de las olas con qué delicia por los rizos lisos resbalas a los verdes paraísos de los senos profundos. Caracolas gimen de amor, sirenas tañen violas y laten peces de oro entre narcisos. (Gerardo Diego, Obras completas, Poesía, Madrid, Santillana, 1996, vol. I, p. 553). 